\title{
A 3 months follow-up of functional dependency, muscle strength, balance and endurance in long- stay icu patients; association with rehabilitation programmes
}

\author{
CM de Jager", A van Wieren, NA Bruins, EC Boerma
}

From ESICM LIVES 2015

Berlin, Germany. 3-7 October 2015

\section{Introduction}

Over the last decades ICU survival is increasing. As a consequence, post ICU sequelae with (persistent) functional dependency in long-stay ICU patients become a topic of interest. However data on specific fields of physical performance and the potential influence of rehabilitation programmes remain scarce [1].

\section{Objectives}

To establish the course of functional dependency and specific fields of physical performance in patients with and without a (non ICU-specific) rehabilitation programme in long-stay ICU patients.

\section{Methods}

We performed a single centre prospective observational study in mixed ICU patients with a length of stay ICU >
48 hours. Patients were evaluated at ICU discharge and reevaluated after a 3-months period in a specific post-ICU outpatient clinic. At both time points a Barthel score (BS) and grip strength (GS) were recorded. Additionally the 6 minutes walking test (6MWT), the Berg balance scale (BBS) and characteristics of individual rehabilitation programmes were assessed in the outpatient setting. Nonparametric tests for comparison between dependent and independent datasets were used. A Bonferroni correction was used for multiple comparison.

\section{Results}

In a 1-year period during 201480 patients were included. Baseline characteristics are provided in Table 1. Overall there was a statistical improvement over time in all functional fields (Table 2). At 3 month 5 patients (6\%) remained fully/severely functionally dependent, 3 (4\%)

Table 1. Baseline characteristics

\begin{tabular}{lllll}
\hline & All $(\mathbf{N}=\mathbf{8 0})$ & Non-rehab $(\mathbf{N}=\mathbf{3 6})$ & Rehab $(\mathbf{N}=\mathbf{3 9})$ & $\mathbf{p}$-value \\
\hline Age (years) & $65[56-73]$ & $65[57-73]$ & $65[56-72]$ & 0.89 \\
\hline APACHE II score & $22[16-30]$ & $21[15-24]$ & $29[24-33]$ & 0.001 \\
\hline Admission type & & & & \\
\hline -elective(\%) & 16 & 17 & 85 & 0.88 \\
\hline -non-elective(\%) & 84 & 83 & $5[3-10]$ & \\
\hline Ventilator days & $4[3-9]$ & $4[2-6]$ & $27[19-34]$ & 0.044 \\
\hline LOS ICU (days) & $23[15-35]$ & $20[13-37]$ & 0.33 \\
\hline
\end{tabular}

Data are presented as median [IQR]. APACHE Acute physiology and chronic health evaluation, LOS Length of stay, Rehab Rehabilitation programme. $P$ value between subgroups (rehab versus non-rehab) 
Table 2. Results

\begin{tabular}{llllll}
\hline & ICU discharge & $\mathbf{3}$ Month all & Without rehab & With rehab & p-value \\
\hline Barthel score, $\mathrm{AU}$ & $12[8-16]$ & $20[18-20]$ & $20[20-20]$ & $20[18-20]$ & ${ }^{\mathrm{a}} 0.006^{\mathrm{b}} 0.84$ \\
\hline Grip strength $\mathrm{L}, \mathrm{KPa},(\%)$ & $18[14-23],(36)$ & $29[23-40],(90)$ & $32[26-40]$ & $26[21-37]$ & ${ }^{\mathrm{a}} 0.006^{\mathrm{b}} 0.90$ \\
\hline Grip strength $\mathrm{R}, \mathrm{KPa},(\%)$ & $19[14-29],(28)$ & $34[24-44],(84)$ & $38[27-46]$ & $28[22-39]$ & ${ }^{\mathrm{a}} 0.006^{\mathrm{b}} 0.16$ \\
\hline 6MWT, m, (\%) & $\mathrm{NA}$ & $420[350-550], 86[68-93]$ & $460[360-554], 87[73-93]$ & $395[338-538], 84[63-93]$ & ${ }^{\mathrm{b}} 1.0$ \\
\hline Berg Balance Scale, AU & $\mathrm{NA}$ & $54[52-56]$ & $54[52-56]$ & $54[50-56]$ & ${ }^{\mathrm{b}} 1.0$ \\
\hline
\end{tabular}

Data are presented as median [IQR] or in percentage of normal values. 6 MWT 6 minutes walking test, Rehab Rehabilitation programme. ${ }^{a}$ comparison between ICU discharge and 3 months after ICU discharge, ${ }^{\text {b }}$ comparison between subgroups with and without rehabilitation programme

were partially functionally dependent, 16 (20\%) became functionally independent with help and $56(70 \%)$ became functionally independent. At this time point grip strength returned to normal in at least 1 hand in $90 \%$, and in both hands in $81 \%$ of patients. The BBS at three months indicated a low fall risk in $97 \%$ of patients. However, the $6 \mathrm{MWT}$ at three months was only normalized in $19 \%$ of patients. $52 \%$ of patients participated in any form of (non ICU-specific) rehabilitation program, $48 \%$ did not take part in any form of rehabilitation programme. There was no statistical difference in any outcome variable of physical performance between patients with and without a rehabilitation program.

\section{Conclusions}

In long-stay ICU patients overall physical performance considerably improved in 3 months from ICU discharge. However, there are large differences in the recovery of specific fields of physical performance, irrespective of participation in non ICU-specific rehabilitation programmes. Further research to unravel the specific rehabilitation needs of long-stay ICU patients is needed.

Published: 1 October 2015

\section{Reference}

1. Jackson JC, et al: Cognitive and physical rehabilitation of intensive care unit survivors: Results of the RETURN randomized controlled pilot investigation. Crit Care Med 2012, 40:1088-1097.

doi:10.1186/2197-425X-3-S1-A442

Cite this article as: de Jager et al: A 3 months follow-up of functional dependency, muscle strength, balance and endurance in long-stay icu patients; association with rehabilitation programmes. Intensive Care Medicine Experimental 2015 3(Suppl 1):A442.

\section{Submit your manuscript to a SpringerOpen ${ }^{\mathcal{O}}$ journal and benefit from:}

- Convenient online submission

- Rigorous peer review

- Immediate publication on acceptance

- Open access: articles freely available online

- High visibility within the field

- Retaining the copyright to your article

Submit your next manuscript at $>$ springeropen.com 